\title{
The atypical anxiolytic drug, tofisopam, selectively blocks phosphodiesterase isoenzymes and is active in the mouse model of negative symptoms of psychosis
}

\author{
Chris Rundfeldt $\cdot$ Katarzyna Socała $\cdot$ \\ Piotr Wlaź
}

Received: 4 June 2010/Accepted: 5 October 2010/Published online: 22 October 2010

(C) The Author(s) 2010. This article is published with open access at Springerlink.com

\begin{abstract}
Tofisopam is a member of the 2,3-benzodiazepine compound family which is marketed for the treatment of anxiety in some European countries. In contrast to classical 1,4-benzodiazepines, the compound does not bind to the benzodiazepine binding site of the $\gamma$-aminobutyric acid receptor and its psychopharmacological profile differs from such compounds. In addition to anxiolytic properties, antipsychotic effects are reported. We now show that tofisopam, $50 \mathrm{mg} / \mathrm{kg}$ intraperitoneally (i.p.), administered in parallel to repeated doses of dizocilpine $0.2 \mathrm{mg} / \mathrm{kg}$ i.p. can ameliorate dizocilpine-induced prolongation of immobility, which is considered to be a model of negative symptoms of psychosis. We further show that tofisopam acts as an isoenzyme-selective inhibitor of phosphodiesterases (PDEs) with highest affinity to PDE-4A1 $(0.42 \mu \mathrm{M})$ followed by PDE-10A1 $(0.92 \mu \mathrm{M})$, PDE-3 $(1.98 \mu \mathrm{M})$ and PDE-2A3 $(2.11 \mu \mathrm{M})$. The data indicate that tofisopam is an interesting candidate for the adjuvant treatment of psychosis with focus on negative symptoms. Combined partial inhibition of PDE-4 and PDE-10 as well as PDE-2 may be the underlying mechanism to this activity. Due to the good safety profile of tofisopam as evident from long-term use of this agent in patients, it may be concluded that dual or triple inhibition of PDE isoenzymes with additive or synergistic effects may be an interesting approach to pharmacological activity, resulting in active compounds with
\end{abstract}

C. Rundfeldt

Drug-Consult.Net, Toepfferspark 2a,

39108 Magdeburg, Germany

K. Socała $\cdot$ P. Wlaź $(\bowtie)$

Department of Animal Physiology, Institute of Biology,

Maria Curie-Skłodowska University, Akademicka 19,

20-033 Lublin, Poland

e-mail: piotr.wlaz@umcs.lublin.pl beneficial safety profile. Dose-limiting side effects such as emesis induced by selective inhibition of PDE-4 may be prevented by such strategies.

Keywords Phosphodiesterase - PDE-2A3 - PDE-4A1 . PDE-10A1 - Psychosis - Neuroleptic - Mouse swim test . Avolition

\section{Introduction}

Tofisopam, a 2,3-benzodiazepine (2,3-BDZs), represent a unique drug among CNS-active compounds. Though sharing a common chemical backbone to 'classical' 1,4-benzodiazepines and though sharing the anxiolytic activity, the compound does not interact with the benzodiazepine binding site of the $\gamma$-aminobutyric acid (GABA) receptor (Petocz 1993). It is an anxiolytic without sedative-hypnotic or muscle relaxant effects. Tofisopam does not impair psychomotor and intellectual performance, like other benzodiazepines do. In contrast, it has a mild cognitive stimulatory activity. It is also potent in alleviating vegetative symptoms accompanying anxiety disorders (Szegő et al. 1993). Tofisopam does not possess anticonvulsive properties and does not induce sleep even in subtoxic doses, and only such subtoxic doses enhance the effect of barbiturates and ethanol. Applying doses above $200 \mathrm{mg} / \mathrm{kg}$ to experimental animals, tofisopam exhibits effects similar to that of neuroleptics (e.g., catalepsy, ptosis, decrease of pentylenetetrazole threshold, potentiation of amphetamine- and apomorphine-induced stereotypy) (Petocz 1993). This unique pharmacological profile lead to the conclusion that tofisopam may be of interest for treatment of psychosis. Current antipsychotics are well capable of ameliorating the positive symptoms of a psychotic episode. If administered chronically, the re-occurrence of such an 
episode can be retarded or even prevented. However, the treatment with classical antipsychotic is hampered with side effects and patient compliance for long-term treatment is often low, potentially due to these side effects. Some of the side effects of such classical antipsychotics overlap with the negative symptoms of psychosis, i.e., the compounds exert negative effects on attention, concentration, cognition and memory (Arnt and Skarsfeldt 1998).

While some 2,3-BDZs and in part also tofisopam have been shown to induce antipsychotic-like effects in classical animal models of psychosis linked to the positive symptoms of the disease, i.e., in the apomorphine climbing test, the conditioned avoidance reaction and-to a lesser extent-in the catalepsy test, the pharmacological profile and the side effect profile of tofisopam in man differs from classical antipsychotics (Horváth et al. 2000). Due to the reported mild stimulatory activity (Szegö et al. 1993) which is in contrast to the activity of classical antipsychotics we were interested to see whether tofisopam may be active in a model of negative symptoms of psychosis, which mimics the state of avolition. A respective model has been described by Noda et al. (1995).

Due to the interesting pharmacological profile of tofisopam we were also interested to learn more about the mechanism of action. Early binding studies identified specific and exclusive binding of 2,3-BDZs within the striatum and associated structures (Horváth et al. 2000). The binding site was named girisopam binding site, since this 2,3-BDZ derivative was found to have the highest affinity. The distribution of this proposed binding site overlaps largely with the distribution of the phosphodiesterase 10 isoenzyme (PDE-10), which is highly and selectively expressed in striatum (Seeger et al. 2003). Furthermore, PDE-10 inhibitors are discussed to be interesting targets for antipsychotic agents (Siuciak et al. 2006). Horváth et al. (2000) proposed that the mechanism of action of tofisopam may be related to alteration in the phosphorylation of protein(s). While inhibition of phosphodiesterase does not directly result in protein phosphorylation, the second messengers-cyclic adenosine monophosphate (cAMP) or cyclic guanosine monophosphate (cGMP)—which are cleaved by phosphodiesterases, can activate protein kinases resulting in increased protein phosphorylation. For these reasons we screened different PDE isoenzymes including PDE-10 for specific interaction with tofisopam.

\section{Materials and methods}

\section{Phosphodiesterase screen}

To screen for interaction with different PDE isoenzymes, tofisopam was analyzed using the IMAP Technology (Molecular Devices Inc., Sunnyvale, CA, USA), as established at Scottish Biomedical, Glasgow, UK. In brief, the assay is based on the high-affinity binding of phosphate by immobilized metal coordination complexes on nanoparticles. The binding reagent complexes with phosphate groups on nucleotide monophosphate generated from cyclic nucleotides (cAMP/cGMP) through phosphodiesterases. With fluorescence polarization detection, binding causes a change in the rate of the molecular motion of the phosphate-bearing molecule and results in an increase in the fluorescence polarization value observed for the fluorescent label attached to the substrate. Using human recombinant protein of PDE-1A3, PDE-2A3, PDE-3A, PDE-4A1, PDE5 (catalytic domain only), PDE-6C, PDE-8A1, PDE-9A1, PDE-10A1 and PDE-11A1, selective inhibition of different isoenzymes was screened using a single-point assay at a concentration of $10,000 \mathrm{nM}$. The assays have been validated using reference PDE inhibitors (MacKenzie et al. 2010). Tofisopam was dissolved in DMSO and diluted in assay buffer, final DMSO concentration $0.1 \%$. Reactions were carried out in duplicate. For isoenzymes where the single-point analysis resulted in an inhibition $>50 \%, \mathrm{IC}_{50}$ was determined using the same method but with an 8-point assay, using 3 parallel experiments for each isoenzyme. The $\mathrm{IC}_{50}$ determination was conducted for PDE-2A3, PDE3A, PDE-4A1 and PDE-10A1.

\section{Animals}

The animal experiments were carried out on a total of 49 male Albino Swiss mice weighing 25-30 g purchased from the licensed breeder (Laboratory Animals Breeding, Górzkowska, Warsaw, Poland). They were used in this study after at least 1 week of acclimatization. The animals were housed in polycarbonate cages in groups of 6-10 under the strictly controlled laboratory conditions (ambient temperature $22-23^{\circ} \mathrm{C}$, relative humidity about $45-55 \%$, 12/12 light/dark cycle, light on at 6:00 h; chow pellets and tap water continuously available). The experimental protocol was approved by the Local Ethics Committee at the Medical University of Lublin (license no. 18/2007), and all the procedures were in strict compliance with the European Communities Council Directive of 24 November 1986 (86/ 609/EEC).

\section{Drugs}

Tofisopam [1-(3,4-dimethoxyphenyl)-5-ethyl-7,8-dimethoxy-4-methyl-5H-2,3-benzodiazepine, racemic mixture, kindly provided by EGIS Pharmaceuticals PLC (Budapest, Hungary)], was freshly suspended in a $0.5 \%$ aqueous solution of methyl cellulose (Sigma, St. Louis, MO, USA) and administered intraperitoneally (i.p.) at a volume of $5 \mathrm{ml} / \mathrm{kg}$. Dizocilpine [(+)-5-methyl-10,11-dihydro- 
H-dibenzocyclohepten-5,10-imine hydrogen maleate, MK801; purchased from Sigma] was dissolved extempore in physiological saline and administered i.p. at a volume of $5 \mathrm{ml} / \mathrm{kg}$. Control animals received respective vehicles at appropriate volumes.

Forced swimming test in mice chronically treated with dizocilpine

Acute administration of the potent $N$-methyl-D-aspartate (NMDA) receptor antagonist phencyclidine can induce both, positive and negative symptoms of psychosis in man and exacerbates psychosis in schizophrenic patients (Abdel-Naby et al. 2001). In animals, phencyclidine can induce a wide range of abnormal behaviors which may be linked to psychotic behavior. Upon repeated administration of phencyclidine, a state of avolition can be induced in mice, which persists for several days after termination of treatment with phencyclidine. Avolition is one of the negative symptoms of schizophrenia; it is quantified in a forced swim test and animals exhibit a state of prolonged immobility as indicator of avolition (Abdel-Naby et al. 2001). This model was proposed to be an ideal model of negative symptoms of psychosis (Noda et al. 1995), it is however limited to the depressive component and may not be useful to model other negative symptoms such as learning and memory deficits or social retract.

Since phencyclidine is a controlled substance, we have re-established the model using the NMDA-receptor antagonist dizocilpine instead. The forced swim test and the drug treatment protocol were carried out on mice essentially as described by Noda et al. (1995). The dose of dizocilpine and the treatment schedule was selected based on preliminary experiments (data not presented). On the first day (Friday), each animal was placed individually into a glass cylinder (height $20 \mathrm{~cm}$, diameter $15 \mathrm{~cm}$ ) containing $11 \mathrm{~cm}$ of water maintained at $23^{\circ} \mathrm{C}$, and was forced to swim for $3 \mathrm{~min}$, and the immobility time was recorded (first measurement of immobility as baseline measurement). The mouse was judged to be immobile when it remained floating passively in the water. For induction of avolition, mice were chronically treated with $0.2 \mathrm{mg} / \mathrm{kg}$ dizocilpine i.p. daily excluding weekends starting on the fourth day (Monday) after the first swim test, until day 19 (Friday). After a 2-day drug-free period, on the 22nd day (Monday), each mouse was placed in water again for $3 \mathrm{~min}$, and the immobility was recorded to test for prolongation of immobility (second measurement of immobility).

For the current experiment, a group of 49 mice was exposed to an initial swim test to determine the individual immobility time. The mice were thereafter randomized to three treatment groups of 16-17 mice. Three days after this baseline swim test, treatment was initiated. One group received the vehicle of dizocilpine and vehicle of tofisopam (vehicle control group); the second group received treatment with dizocilpine $0.2 \mathrm{mg} / \mathrm{kg}$ once daily plus tofisopam-vehicle twice daily on 5 days per week (psychosis control), and a third group dizocilpine $0.2 \mathrm{mg} / \mathrm{kg}$ once daily plus tofisopam $50 \mathrm{mg} / \mathrm{kg}$ twice daily on 5 days per week until experimental day 19. The treatment schedule consisted of two administrations of tofisopam at a dose of $50 \mathrm{mg} / \mathrm{kg}$ i.p. each, given $4 \mathrm{~h}$ apart. The first dose was given $10 \mathrm{~min}$ before the daily dizocilpine dose. The 4-h break between two tofisopam administrations was selected based on the rapid absorption and short half-life of tofisopam (Klebovich and Abermann 1993) to safely cover the duration of action of dizocilpine. After a washout of 2 days, a second quantification of immobility was conducted on day 22 , about $72 \mathrm{~h}$ after the last dizocilpine dose and $68 \mathrm{~h}$ after the last tofisopam dose. This washout period was selected to ensure that animals are free of both, tofisopam and dizocilpine plasma levels. The half-life of dizocilpine in rodents is reported to be in the range of $2 \mathrm{~h}$ (Vezzani et al. 1989).

\section{Statistical analysis}

All data are presented as means \pm standard error of the mean (SEM), where appropriate. Statistical analysis of the effect of tofisopam on the prolonged immobility after termination of treatment was performed by one-way analysis of variance (ANOVA) of the individual differences between the two measurements of immobility followed by Tukey's post hoc test. The use of individual differences results in a baseline adjustment. A $p$ value less than or equal to 0.05 was considered statistically significant.

To test for effects of repeated determination of immobility in the same group, individual groups were also compared using paired $t$ test.

\section{Results}

Phosphodiesterase screen (Table 1)

Tofisopam was found to act as low-affinity blocker of a number of PDE isoenzymes. While no interaction was found with PDE-6, PDE-8, PDE-9, and PDE-11, weak inhibition was identified for PDE-1 and PDE-5. Due to an inhibition of less than $50 \%$ measured at $10,000 \mu \mathrm{M}$, no $\mathrm{IC}_{50}$ was determined for these isoenzymes. Inhibition in the high nanomolar to low micromolar range was found for PDE-2A3 $(2.11 \pm 1.8 \mu \mathrm{M})$, PDE-3A $(1.98 \pm 1.7 \mu \mathrm{M})$, PDE-4A1 $(0.42 \pm 0.8 \mu \mathrm{M})$, and PDE-10A1 $(0.92 \pm 1.2 \mu \mathrm{M})$. 
Table 1 Inhibition of phosphodiesterase (PDE) isoenzymes by tofisopam

\begin{tabular}{lll}
\hline PDE isoenzyme & \% inhibition at $10,000 \mathrm{nM}$ & $\mathrm{IC}_{50}(\mu \mathrm{M})$ \\
\hline PDE-1A3 & 37.8 & n.d. \\
PDE-2A3 & 83.4 & $2.11 \pm 1.8$ \\
PDE-3A & 81.7 & $1.98 \pm 1.7$ \\
PDE-4A1 & 92.1 & $0.42 \pm 0.8$ \\
PDE-5 (catalytic domain) & 42.0 & n.d. \\
PDE-6C & 5.3 & n.d. \\
PDE-8A1 & 7.9 & n.d. \\
PDE-9A1 & 2.8 & n.d. \\
PDE-10A1 & 89.6 & $0.92 \pm 1.2$ \\
PDE-11A1 & 4.2 & n.d.
\end{tabular}

Effect of tofisopam (10,000 nM) on activity of different PDE isoenzymes, as determined using the IMAP Technology (Molecular Devices, Inc., Sunnyvale, CA, USA). Percent inhibition values were determined from double determinations. For isoenzymes where the inhibition exceeded $50 \%, \mathrm{IC}_{50}$ values were determined with an 8-point assay, using 3 parallel experiments for each individual isoenzyme. $\mathrm{IC}_{50}$ values are given as means \pm standard error of the mean of 3 measurements

Effects of tofisopam in a model of negative symptoms of psychosis (Fig. 1)

The animals of all three treatment groups had similar immobility times at the pre-test. In addition, the immobility time of vehicle-treated animals was compared between the pre-test and the second measurement on day 22 and the immobility time was similar for both assessments, with $95.2 \mathrm{~s}$ at the first measurement and 103.2 at the second measurement (not significant, paired $t$ test), indicating that repeated measurement of immobility had no effect on immobility time. As expected, animals which had received repeated doses of dizocilpine showed a significant prolongation of the immobility time, with $92.0 \mathrm{~s}$ at the first test and $128.2 \mathrm{~s}$ at the second test. This difference was highly significant $(p<0.001$, paired $t$ test) and the data indicate that the model could be established successfully.

To evaluate the effect of subchronic treatment of tofisopam on the avolition representing as prolonged immobility induced by repeated administration of dizocilpine, the individual differences of the immobility times determined during the first measurement on day 1 and second measurement on day 22 were calculated and compared using one-way analysis of variance (ANOVA). It became evident that treatment with tofisopam in parallel to treatment with dizocilpine ameliorated the prolonged immobility time. The immobility of this group amounted to $117 \mathrm{~s}$ and was not significantly different from the vehicle control group. In contrast, the immobility of the mice treated with dizocilpine was significantly prolonged
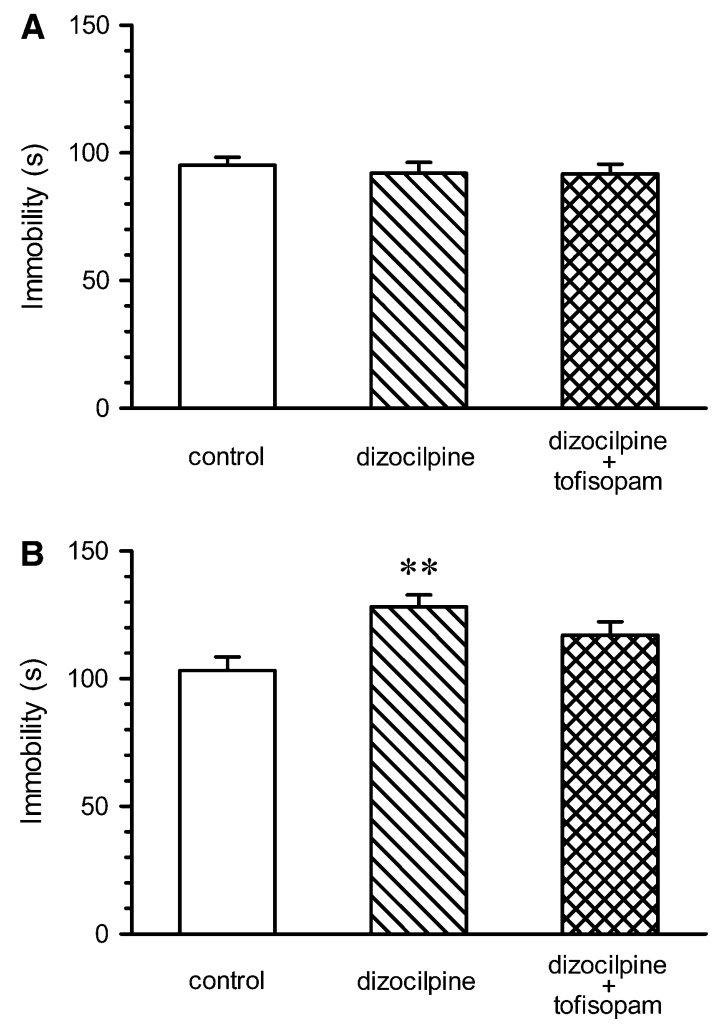

Fig. 1 Immobility of mice in the forces swim test prior to repeated administration of dizocilpine $(0.2 \mathrm{mg} / \mathrm{kg}$ i.p. once daily 5 days per week) or dizocilpine plus tofisopam, $50 \mathrm{mg} / \mathrm{kg}$ i.p. twice daily, 5 days per week (panel a) and on day 22, 3 days after cessation of drug treatment (panel b). Immobility on day 1 was similar for all three groups [ANOVA: $F(2,46)=0.2696$, not significant]. On day 21 (panel b), immobility of the dizocilpine-treated mice was significantly increased if compared to the control group; ANOVA on individual differences: $F(2,46)=6.005, p=0.0048$. The immobility of the tofisopam-treated group was not significantly different from the vehicle group. ${ }^{* *} p<0.004$ versus respective control group (Tukey's post hoc test)

[ANOVA on individual differences: $F(2,46)=6.005$, $p=0.0048$; Tukey's post hoc test: $p<0.004]$.

\section{Discussion}

Tofisopam is an atypical 2,3-benzodiazepine which does not bind to benzodiazepine receptors and which is devoid of CNS side effects characteristic of 1,4-benzodiazepines. The molecule has one chiral centre. Tofisopam was marketed in the racemate form and it was orally administered at $300 \mathrm{mg} /$ day for its anxiolytic properties (Bernard et al. 2008).

The clinical success of tofisopam initiated further chemical and pharmacological investigations resulting in structurally related derivatives (Láng et al. 1985). Among them, the most active compounds show beside their tranquilizing (anti-aggressive) character particular pharmacological properties reminiscent of both anxiolytics and 
atypical neuroleptics (Andrási et al. 1987; Horváth et al. 1989).

The 2,3-BZDs tofisopam, nerisopam and girisopam were shown to specifically bind to a binding site in the striatum and related brain regions (Horváth et al. 1994). This binding site was identified as girisopam binding site (Horváth et al. 2000). The molecular correlate of that binding site could however not be identified to date. Compounds with affinity to the binding site were found to be active in models of anxiety including elevated maze, lick conflict test, light-dark box, and anti-aggressive behavior in fighting mice and in models of psychosis, i.e., in the apomorphine climbing test, the conditioned avoidance reaction and-only at high doses-in the catalepsy test. The pattern of distribution of this binding site largely overlaps with the distribution of the PDE-10 isoenzyme (Seeger et al. 2003). PDE-10 was recently shown to be a very interesting target for antipsychotic activity and drug development programs are ongoing to identify novel PDE10 inhibitors (Schmidt et al. 2008).

We now show that tofisopam acts as an inhibitor of phosphodiesterases with some selectivity for PDE 2, 3, 4 and 10 and affinities in the range of $0.42-2.1 \mu \mathrm{M}$. Activity of tofisopam as PDE inhibitor was reported previously, supporting the findings of our study for PDE1 to PDE5 (Bernard et al. 2008). Recently, it could be also shown that tofisopam blocks PDE-10A isoenzymes with an affinity of $264 \mathrm{nM}$ for the racemate without stereo-selectivity (Nielsen et al. 2007). The same group reported affinity to the PDE4D isoenzymes with affinity of $S(-)$-tofisopam of $117 \mathrm{nM}$ and $R(+)$-tofisopam of $1,257 \mathrm{nM}$.

Phosphodiesterases are widely distributed throughout the body, and they serve diverse functions. While PDE-3 is known to selectively affect cardiac contractility by increasing the intracellular level of cyclic adenosine monophosphate (Goenen 1989), the other three phosphodiesterases targeted by tofisopam have potent CNS activity, and more specifically are discussed to be useful for amelioration of symptoms of psychosis. The oldest phosphodiesterase target for treatment of symptoms of psychosis is the PDE-4 isoenzyme. Rolipram, being the prototype PDE4 inhibitor, was shown to have not only antidepressant and immune modulator, but also antipsychotic and cognitive enhancing activity (Kanes et al. 2007). However, the clinical utility of rolipram and other PDE-4 inhibitors is hampered by the fact that these compounds induce emesis, nausea and gastrointestinal side effect. Roflumilast is the only selective potent PDE4 inhibitor which is submitted for marketing approval for the treatment of chronic obstructive pulmonary disease, albeit with a narrow margin of safety (Field 2008). Roflumilast, however, is not published to be active in behavioral models of CNS diseases and it is not known whether roflumilast can penetrate the brain. The compound has a plasma protein binding of $98.9 \%$ (Bethke et al. 2007).

The discovery that PDE-10 is selectively expressed in medium spiny neurons of the striatum and the correlation of PDE-10 function with dopaminergic neurotransmission has placed PDE-10 as a highly interesting novel target for treatment of psychosis (Siuciak et al. 2006). PDE-10 inhibitors exhibit a broad spectrum of antipsychotic activity in different animal models (Siuciak et al. 2006; Siuciak 2008; Schmidt et al. 2008). Both, effects in models of positive and negative symptoms are reported. The pharmacological activity could be correlated not only to an inhibition of the D2-receptor-dominated pathways, but also to a facilitation of the D1-receptor-dominated prefrontal pathways. This combination of activity is believed to be highly interesting for the amelioration of negative symptoms of psychosis (Siuciak 2008). The target is subject to drug discovery programs, but none of these programs has reached a state of proof of efficacy in patients (Verhoest et al. 2009).

The PDE-2 isoenzyme is a further candidate for the treatment of symptoms of psychosis, however, with focus on the memory impairment contributing to the negative symptoms of psychosis (Boess et al. 2004; DomekŁopacińska and Strosznajder 2008). Furthermore, anxiolytic effects may be mediated by PDE-2 inhibition (Masood et al. 2009).

We now show that tofisopam acts as a mixed blocker of all three psychosis treatment related targets. The affinity of tofisopam to these isoenzymes is in the same range or even higher than the affinity of rolipram which was found to have an affinity of $1.1 \mu \mathrm{M}$ (Bernard et al. 2008). While tofisopam remains to be a low-affinity PDE inhibitor if compared with modern PDE inhibitors, it is possible that the pharmacological activity is mediated by its interaction with some or all of these phosphodiesterase isoenzymes. In volunteers administered a single dose of $100 \mathrm{mg}$ tofisopam, a maximal plasma level of $328.8 \mathrm{ng} / \mathrm{ml}$ was reached, equal to about $0.9 \mu \mathrm{M}$. The apparent volume of distribution ranged from 523.8 to $5,154.11^{-1}$ indicating that tofisopam has higher concentration in extravascular tissue than in the vascular compartment. The half-life was found to be in the range of $4 \mathrm{~h}$, indicating that upon three times daily administration of $100 \mathrm{mg}$ some accumulation can be expected (Tóth et al. 2006). These data indicate that the steady-state tissue concentration can be expected to be in the range of or even higher than the $\mathrm{IC}_{50}$ of PDE-4, PDE10 , and potentially also PDE-2 resulting in a partial block of these enzymes.

In the in vivo model, the repeated administration of dizocilpine lead to the expected prolongation of immobility in the mice tested. It should be noted that the reactivity of the mice cannot be correlated to an acute drug-effect of dizocilpine, which is known to induce hyperactivity if 
administered to animals. Due to the washout time of 3 days after the last dose and in view of the half-life of dizocilpine in rodents in the range of $2 \mathrm{~h}$ (Vezzani et al. 1989), the behavioral modification of the mice may rather be correlated to a chronic plasticity. Our data indicate that the model initially described using phencyclidine can be generated using dizocilpine instead (Noda et al. 1995).

Tofisopam, administered twice daily to the mice, was capable of reducing the increased immobility in our model. The effect was evident 3 days after the last dose of tofisopam, indicating that the effect cannot be related to an acute effect of tofisopam on mouse behavior. The enhancement of immobility induced by subchronic administration of NMDA antagonists is attenuated by clozapine and risperidone, which are known to improve negative symptoms in patients, but not by haloperidol, which does not improve them (Noda et al. 1995, 2000). Tofisopam thus bears the potential to ameliorate negative symptoms of psychosis such as avolition; however, no complete normalization could be obtained. This may be related to the short half-life of tofisopam in rodents, but further experiments are needed to evaluate the potential of tofisopam or other (more potent) 2,3-BZDs in psychosis. Other models of negative symptoms of psychosis should be also employed to evaluate whether negative symptoms beyond avolition are also modified.

It may be discussed which phosphodiesterase isoenzymes may be responsible for the observed pharmacological action in mice. Both, PDE-4 and PDE-10 isoenzymes are involved in pharmacological action which may result in effects on negative symptoms of psychosis. Siuciak reviewed in 2008 the role of phosphodiesterases in psychosis and she concludes that both isoenzymes bear great potential for the treatment of positive symptoms, negative symptoms and/or cognitive deficits associated with schizophrenia (Siuciak 2008). Drugs targeting both targets may be of even higher interest. While the potential of such dual inhibitors has not yet been explored systematically and while no CNS-active drugs with selectivity for PDE-4 or PDE-10 are marketed so far, the availability of tofisopam enables a first insight in the potential of such dual inhibitors. Furthermore, the additional inhibition of PDE-2 may also contribute to the overall activity, adding anxiolytic effects and potentially also positive effects on cognitive function. Tofisopam is not afflicted with the well-known side effects of selective PDE-4 inhibitors. While Bernard et al. (2008) discuss that tofisopam may represent a novel structural class of tolerated PDE-4 inhibitors without emetogenic potential, an alternative explanation to the good tolerability may be that the combination of a partial block of multiple PDEs with additive or even synergistic pharmacological effects results in the observed pharmacology, while preventing the toxicity known from highly selective and potent compounds, dosed to induce a complete block of individual enzymes.

Other 2,3-BZDs may be systematically evaluated for their interaction with PDE isoenzymes and compounds with combined affinity to PDE-4 and PDE-10, but also to PDE-2 may be tested in respective animal models, with focus on dual or even triple inhibitors.

Acknowledgments The authors wish to thank EGIS Pharmaceuticals PLC (Budapest, Hungary) for a generous gift of tofisopam.

Conflict of interest The authors declare they have no conflict of interest.

Open Access This article is distributed under the terms of the Creative Commons Attribution Noncommercial License which permits any noncommercial use, distribution, and reproduction in any medium, provided the original author(s) and source are credited.

\section{References}

Abdel-Naby SM, Noda Y, Mahmoud HM, Mamiya T, Nagai T, Furukawa H, Nabeshima T (2001) Enhancement of immobility induced by repeated phencyclidine injection: association with cFos protein in the mouse brain. Behav Brain Res 124:71-76

Andrási F, Horváth K, Sineger E, Berzsenyi P, Borsy J, Kenessey A, Tarr M, Láng T, Körösi J, Hámori T (1987) Neuropharmacology of a new psychotropic 2,3-benzodiazepine. Arzneimittelforschung 37:1119-1124

Arnt J, Skarsfeldt T (1998) Do novel antipsychotics have similar pharmacological characteristics? A review of the evidence. Neuropsychopharmacology 18:63-101

Bernard P, Dufresne-Favetta C, Favetta P, Do QT, Himbert F, Zubrzycki S, Scior T, Lugnier C (2008) Application of drug repositioning strategy to TOFISOPAM. Curr Med Chem 15:3196-3203

Bethke TD, Bohmer GM, Hermann R, Hauns B, Fux R, Morike K, David M, Knoerzer D, Wurst W, Gleiter CH (2007) Doseproportional intraindividual single- and repeated-dose pharmacokinetics of roflumilast, an oral, once-daily phosphodiesterase 4 inhibitor. J Clin Pharmacol 47:26-36

Boess FG, Hendrix M, van der Staay FJ, Erb C, Schreiber R, van Staveren W, de Vente J, Prickaerts J, Blokland A, Koenig G (2004) Inhibition of phosphodiesterase 2 increases neuronal cGMP, synaptic plasticity and memory performance. Neuropharmacology 47:1081-1092

Domek-Łopacińska K, Strosznajder JB (2008) The effect of selective inhibition of cyclic GMP hydrolyzing phosphodiesterases 2 and 5 on learning and memory processes and nitric oxide synthase activity in brain during aging. Brain Res 1216:68-77

Field SK (2008) Roflumilast: an oral, once-daily selective PDE-4 inhibitor for the management of COPD and asthma. Expert Opin Investig Drugs 17:811-818

Goenen M (1989) Historical perspectives and update of amrinone. J Cardiothorac Anesth 3:15-23

Horváth K, Andrási F, Berzsenyi P, Pátfalusi M, Patthy M, Szabó G, Sebestyén L, Bagdy E, Körösi J, Botka P, Hámori T, Láng T (1989) A new psychoactive 5H-2,3-benzodiazepine with a unique spectrum of activity. Arzneimittelforschung 39:894-899

Horváth EJ, Palkovits M, Lenkei Z, Gyüre KI, Fekete MI, Arányi P (1994) Autoradiographic localization and quantitative determination of specific binding sites of anxiolytic homophthalazines 
(formerly called 2,3-benzodiazepines) in the striato-pallidonigral system of rats. Brain Res Mol Brain Res 22:211-218

Horváth EJ, Horváth K, Hámori T, Fekete MI, Sólyom S, Palkovits M (2000) Anxiolytic 2,3-benzodiazepines, their specific binding to the basal ganglia. Prog Neurobiol 60:309-342

Kanes SJ, Tokarczyk J, Siegel SJ, Bilker W, Abel T, Kelly MP (2007) Rolipram: a specific phosphodiesterase 4 inhibitor with potential antipsychotic activity. Neuroscience 144:239-246

Klebovich I, Abermann M (1993) Pharmacokinetics and metabolism of tofizopam (Grandaxin). Acta Pharm Hung 63:83-90

Láng T, Kőrösi J, Zólyomi G, Hámori T, Botka P (1985) Design and synthesis of 5H-2,3-benzodiazepines. In: Vizi ES, Furst S, Zsilla G (eds) Proc. 4th Cong. Hung. Pharmacol. Soc., Pergamon Press and Publishing House of the Hungarian Academy of Sciences, Oxford and Budapest, pp 91-97

MacKenzie S, Hastings S, Wells C (2010) Cyclic nucleotide phosphodiesterase assay technology. Curr Protoc Pharmacol 49:3.12.1-3.12.26

Masood A, Huang Y, Hajjhussein H, Xiao L, Li H, Wang W, Hamza A, Zhan CG, O'Donnell JM (2009) Anxiolytic effects of phosphodiesterase-2 inhibitors associated with increased cGMP signaling. J Pharmacol Exp Ther 331:690-699

Nielsen EB, Kehler J, Nielsen J, Brøsen P (2007) Patent: use of tofisopam as a PDE10A inhibitor. WO 2007/082546 A1

Noda Y, Yamada K, Furukawa H, Nabeshima T (1995) Enhancement of immobility in a forced swimming test by subacute or repeated treatment with phencyclidine: a new model of schizophrenia. $\mathrm{Br}$ J Pharmacol 116:2531-2537

Noda Y, Kamei H, Mamiya T, Furukawa H, Nabeshima T (2000) Repeated phencyclidine treatment induces negative symptomlike behavior in forced swimming test in mice: imbalance of prefrontal serotonergic and dopaminergic functions. Neuropsychopharmacology 23:375-387

Petocz L (1993) Pharmacologic effects of tofizopam (Grandaxin). Acta Pharm Hung 63:79-82

Schmidt CJ, Chapin DS, Cianfrogna J, Corman ML, Hajos M, Harms JF, Hoffman WE, Lebel LA, McCarthy SA, Nelson FR, ProulxLaFrance C, Majchrzak MJ, Ramirez AD, Schmidt K, Seymour
PA, Siuciak JA, Tingley FD III, Williams RD, Verhoest PR, Menniti FS (2008) Preclinical characterization of selective phosphodiesterase 10A inhibitors: a new therapeutic approach to the treatment of schizophrenia. J Pharmacol Exp Ther 325:681-690

Seeger TF, Bartlett B, Coskran TM, Culp JS, James LC, Krull DL, Lanfear J, Ryan AM, Schmidt CJ, Strick CA, Varghese AH, Williams RD, Wylie PG, Menniti FS (2003) Immunohistochemical localization of PDE10A in the rat brain. Brain Res 985:113-126

Siuciak JA (2008) The role of phosphodiesterases in schizophrenia: therapeutic implications. CNS Drugs 22:983-993

Siuciak JA, Chapin DS, Harms JF, Lebel LA, McCarthy SA, Chambers L, Shrikhande A, Wong S, Menniti FS, Schmidt CJ (2006) Inhibition of the striatum-enriched phosphodiesterase PDE10A: a novel approach to the treatment of psychosis. Neuropharmacology 51:386-396

Szegö J, Somogyi M, Papp E (1993) Excerpts from the clinicalpharmacologic and clinical studies of Grandaxin. Acta Pharm Hung 63:91-98

Tóth M, Bereczki A, Drabant S, Nemes KB, Varga B, Grézal G, Tömlő J, Lakner G, Klebovich I (2006) Gas chromatography nitrogen phosphorous detection (GC-NPD) assay of tofisopam in human plasma for pharmacokinetic evaluation. J Pharm Biomed Anal 41:1354-1359

Verhoest PR, Chapin DS, Corman M, Fonseca K, Harms JF, Hou X, Marr ES, Menniti FS, Nelson F, O'Connor R, Pandit J, ProulxLaFrance C, Schmidt AW, Schmidt CJ, Suiciak JA, Liras S (2009) Discovery of a novel class of phosphodiesterase 10A inhibitors and identification of clinical candidate 2-[4-(1-methyl4-pyridin-4-yl-1H-pyrazol-3-yl)-phenoxymethyl]-quinoline (PF2545920) for the treatment of schizophrenia. J Med Chem 52:5188-5196

Vezzani A, Serafini R, Stasi MA, Caccia S, Conti I, Tridico RV, Samanin R (1989) Kinetics of MK-801 and its effect on quinolinic acid-induced seizures and neurotoxicity in rats. J Pharmacol Exp Ther 249:278-283 